\title{
Physical Activity Trends in Millenial Generation: Kill the Body Fat
}

\author{
Linda Desrianda Tamher ${ }^{1}$, Giat Akbar Maulana ${ }^{2}$, Mustika Fitri ${ }^{3}$, Pipit Pitriani ${ }^{4}$ \\ \{lindadesrianda@upi.edu ${ }^{1}$, giat.akbar.maulana@gmail.com², mustikafitri@upi.edu ${ }^{3}$ \} \\ Universitas Pendidikan Indonesia, Bandung, Indonesia ${ }^{1234}$
}

\begin{abstract}
Lack of physical activity and unhealthy lifestyles is no stranger to the current millennial generation. so many of them are gaining weight until they are obese. One of the characteristics of obesity is an increase in body fat percentage. Physical activity is a good way to reduce body fat percentage. The aim of the study was to examine physical activity trends in the millennial generation to decrease body fat. It used a pre-posttest two treatment design, with 22 samples of obese women, and divided into aerobic dance group and Zumba group. It was conducted 3 times in a week along 12 weeks, with intensity of $65 \%-85 \%$ based on maximum heart rate. The result of this study showed that aerobic dance and Zumba had an effect on body fat percentage.
\end{abstract}

Keywords: physical activity, body fat percentage, obese women.

\section{Introduction}

Obesity is one of the serious diseases in the world [1]. More than 312 million people obesity [2], with a percentage of $13 \%$ of adults over 18 years old [3], than adolescence 12-19 years old [4]. Increasing age can decrease muscle mass and increased body fat mass [5].

Obesity can be seen from the body composition [6]. One characteristic of obesity has increased the bodyweight, indirectly increasing the percentage of body fat [7]. The normal category range body fat for men is $8.0-19.9 \%$, and for women is $21.0-32.9 \%$, and high category for men is $20.0 \%-24.9 \%$, and for women is $33 \%$ $38.9 \%$, very high category for men is $>25 \%$ and for women $>39.0 \%$ [8]. More severe obesity occurs for women than men [9]. The significant research for different percentage obese men $8-30 \%$ and for women $8-52 \%$ on Southeast Asia [10]. Increased prevalence of obesity worldwide by reaching $18 \%$ in men and exceeding $21 \%$ in women and severe obesity will exceed $6 \%$ in men and $9 \%$ in women [11]. Women tend to exhibit poorer complications than sedentary lifestyles than men [12]. Obesity makes more diseases like diabetes type II, hypertension, chronic disease, dyslipidemia, coronary heart disease, and certain types of cancer [11], reproductive disorder [13], even until mortality [14]. Obesity has more effect on women than men [9].

Some studies have analyzed factors that are at risk in adulthood, such as increasing consumption of unhealthy foods, decreased physical activity, resulting in the development of obesity [4]. An unhealthy lifestyle is the main factor in obesity 
[1]. Lack of physical activity is assumed with the global development and due to lifestyle changes, can negatively affect personal health and society [15]It is known that lack of exercise, unhealthy lifestyles, and poor nutrition causes major health problems such as hypertension, obesity, muscular atrophy, and postural disorders [15]. Lack of physical activity has been linked to increased obesity through frequent sit-down and a lack of physical activity [16]The lack of this activity is caused by the work activity that demands them to dwell in a place for several hours so that it is less moving, and the lack of a walk although the intended place is not too far away [17]. A sedentary lifestyle has a negative effect on health and quality of life [5].

Physical activity programs are one of the most appropriate ways to achieve health benefits [18], increased memory, and chronic disease reduction [19]. Physical activity affects muscle performance and energy expenditure to maintain body composition and reduce the risk of obesity [20]. Increasing physical activity in the form of aerobic exercise leads to increased aerobic capacity in the body [21], thus making the body ideal [22]. It is recommended for every teenager and adult to engage in moderate-intensity physical activity for 60 minutes daily to prevent hypertension and obesity [23]. The duration of $>30$ minutes is a mild intensity zone by using an energy system from oxidation, resulting in an anaerobic bioenergetic contribution of 5-2\% Alaktasid and $95-98 \%$ aerobic. It is therefore suggested that physical activity for durability is done with a long duration with mild intensity, so it is called as Aerobic exercise [24]. Moderate - to high - intensity aerobic exercise significantly reduced body fat in obese boys and girls [6].

Aerobic exercises describe positive changes in body composition, such as a reduction in Body mass index (BMI) and body fat percentage (BF\%) [25]. Aerobic exercise can improve insulin action, improve lipid profile, glycemic levels, blood pressure, reduce the risk of cardiovascular disease, lower body weight, mortality reduction, prevent diabetes complications and improve the quality of life of diabetics if done continuously [26]. Aerobic exercise is one sport that emphasizes a series of repetitive movements and a long duration and nonstop because it refers to the uptake of energy through fat (Giriwijoyo, 2017). Aerobic sports include walking, jogging, swimming, cycling and aerobic gymnastics [27], [28]. An interesting and exciting physical activity today is aerobic dance (Ahmad, Amir, \& Rosli, 2015), such as aerobics dance and zumba.

Now, Zumba ${ }^{\circledR}$ is regarded as one of the most popular high-impact physical activities among women [29]. Zumba exercises are an uplifting, effective, easy-tofollow dance fitness party, inspired by the Latinos, burning calories that drive millions towards excitement and health [30]. Scientific research on the benefits of Zumba in healthy women has shown many positive things, the effect of this type of exercise on body composition and physical fitness (Delextrat, Warner, Graham, \& Neupert, 2016). The application of Zumba Fitness ${ }^{\circledR}$ seems to be as effective as Zumba Fitness ${ }^{\circledR}$ Weight-loss Reduction training [31]. Besides, the average energy expenditure of zumba sports is $369 \mathrm{kcal}$ for each class (duration of approximately 40 minutes), therefore Zumba meets the recommendations of the American College of Sport Medicine of sports at all ages (Tugusi et al., 2018). 
In this study to know the benefits of aerobic gymnastics and Zumba on decreased body fat percentage. The study aims to identify the influence of physical activity on body fat percentage. Researchers have hypothesized that in 12 weeks of physical activity will affect body fat percentage.

\section{$2 \quad$ Materials and Methods}

\subsection{Participants}

This study used experimental research with Pretest-Posttest Two Treatment Design design. The study subject of 22 obese women in the S Fitness Center. The subject has the criteria: (1) active member, (2) has Bodyfat $>30 \%-45 \%$. (3) Have a commitment and passion, (4) have no history of chronic diseases.

\subsection{Study Design}

The subject is divided into two groups given different trainings. Group 1 was given an aerobic gymnastics training and Group 2 was given Zumba gymnastics. The entire subject performs an initial test before training and the final test after completion of the last training. Training is done every $3 \mathrm{x}$ a week (Tugusi, Manca, Bergamin, \& Blasio, 2018) for 12 weeks (Delextrat et al., 2016). With an intensity of 65\%-85\% (Giriwijoyo, 2017), according to the maximum heart rate of each sample.

\subsection{Exercise Method Protocol}

Each-each training program in aerobic gymnastics and Zumba given a division of 10 minutes of heating, 45 minutes of core movement according to the intensity needed, 5 minutes of cooling, of course this intensity is adjusted to the situation and condition of the subject.

\subsection{Measured Variables}

\section{- Omron Karada Scale}

This tool serves to measure body fat, body age, BMI, Visceral fat, Skeletal muscle, and resting metabolism. The way is to focus the data that has been input on tools such as gender, age, height, and weight. How to include weight, height, and age in the appliance, the subject of standing on the position of the upright straight above, while holding the grip of the appliance, then the result will be legible on the device.

\section{- Check Pulse}

Pulsing the pulse in the left hand, or on the neck or in the chest using the right palm of the hand. Performed for 6 seconds, the result is in multiply 10. To be accumulated in 1 minute. 
- Roll meter

This roll meter is used to measure the resulting decline after conducting exercise programs on the limbs, such as the arms, chest, abdomen, thighs, buttocks, and waist in $\mathrm{cm}$ units.

\subsection{Data Analysis}

Analysis of this research data using the Statistical Package for Social Science (SPSS) Ver. 16.0 application. This study using parametric statistics with the analysis of Paired Sample T-Test

\section{$3 \quad$ Results and Discussions}

Based on the results of data from preliminary tests, aerobic gymnastics and Zumba training for 12 weeks and the final Test with the results of the cycle data period:

Table 1. Average and standard deviation group Aerobic Dance And Zumba Based On Body Fat Procentage

\begin{tabular}{lllllll}
\hline \multirow{2}{*}{ Group } & pretest & \multicolumn{3}{c}{ posttest } & \multicolumn{3}{c}{ Paired sample } \\
\cline { 2 - 5 } & Mean & Stdev & Mean & Stdev & T-Test (2-sig) & Sig \\
\hline Aerobic dance & $38 \%$ & $2 \%$ & $31 \%$ & $2.02 \%$ & 0.014 & 0.007 \\
Zumba & $37 \%$ & $2.5 \%$ & $30.5 \%$ & $3.6 \%$ & 0.050 & 0.0025 \\
\hline
\end{tabular}

Table 1 explains the average initial test of the body fat percentage of aerobic gymnastics group $38 \%$ with a standard deviation of $2 \%$, while the average test of the initial Zumba group is $37 \%$ with a standard deviation of $2.5 \%$. After the training conducted aerobic gymnastics and Zumba there is an average final test of the body fat percentage of aerobic gymnastics group is $31 \%$ with the standard deviation of $2.02 \%$, while the average test of the end of the Zumba group is $30.5 \%$ with the standard deviation of $3.6 \%$. 


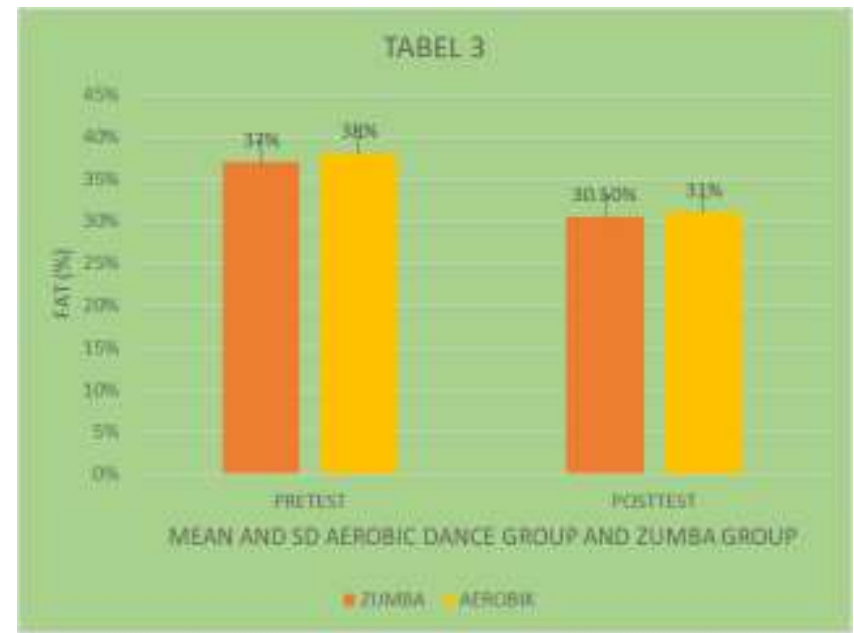

Fig. 1. Comparison Of Body Fat Percentage Of Aerobic Gymnastics And Zumba Group (Average Data \pm SD)

Based on Figure 3, decreased body fat percentage of aerobic gymnastics Group by $7 \%$, and decreased body fat percentage in Zumba group amounted to $6.5 \%$. Result of data calculation using Paired sample T-Test shows in aerobic gymnastics group SIG $(0.0007)<0.05$ and on Zumba SIG Group $(0.0025)<0.05$. These results indicate there is a significant influence on aerobic gymnastics exercises and Zumba against decreased body fat percentage.

Based on the results of research obtained there is a significant influence for physical activity of both aerobic gymnastics and Zumba against decreased body fat percentage. The study conducted for approximately 3 months with 36 sessions resulting in a decrease in the results of body composition measurements in each sample. Based on the data in the tables above it is explained that body composition ranging from body weight, body mass index, fat percentage, muscle to the measurement of the body showed a decrease.

Decreased fat percentage there was a decrease in aerobic gymnastics group $1.06 \%$ while the Zumba group amounted to $1.49 \%$. Zumba Group is seen more of his decline in aerobic gymnastics group of $0.43 \%$. In addition, weight loss and body fat are also affected by the results of the body mass index obtained by each sample. This decline is caused by aerobic and Zumba gymnastics activities conducted for 60 minutes each meeting, aerobic gymnastics and Zumba is a group of physical activity aimed at losing weight, body fat and increase endurance [32].

The data of the decline when compared between aerobic gymnastics and Zumba groups is more or less the same data. But it looks a little bigger the decline is in the Zumba group. This is caused by Zumba as an effective exercise program for improving body composition, aerobic capacity, and general health, it can be a very interesting and effective program to encourage physical activity [31]. So it can be done vigorously. 
Aside from aerobic and Zumba gymnastics, physical activity such as fast roads, jogging, stair climbing, basketball, racket sports, football, lap laps, skating, lawn mowing, cycling, and dancing [33] is an aerobic exercise that is recommended for adults to lower body weight, mass index and body fat. Without realizing daily activities can be used as physical activities that can reduce body mass index, body fat, and body Betar, such as playing, working, traveling, recreation etc [33]. However, if you want maximum results, it is advisable to carry out physical activity with long duration and moderate to high intensity [24].

The physical activity of aerobic and Zumba gymnastics almost has similarities to the results obtained. However, to achieve maximum results is better combined with nutritional intake activity [31]. Because of this body composition can be modified using physical activity and nutritional intake [34]. This is important because the optimal body composition is capable of maintaining the health of cardiometabolic diseases [35]. In addition, changing lifestyles for the better is also one way to destroy the risk of obesity and future Diabetes [36]. Physical activity is important in energy balance and recovery for obese people, but it is better balanced with the regulation of the calories consumed [37].

In fact, this research can result in a reduction in body fat percentage which is even greater in body composition, but there are limited researchers in the study, such as long research time, less conducive situation and condition, the condition of each sample that can not be predicted. In this study it is better for researchers to then be able to consider the situation and conditions in the study, the condition of each sample, and add things to be researched such as nutrition, genetic, daily activities, history of disease and hormones, because it is a factor that affects the body composition.

\section{Conclusions and Suggestions}

In this study obtained a significant reduction of physical activity such as aerobic gymnastics and Zumba for decreased body fat percentage.

\section{References}

[1] N. Kapoor et al., "Normal Weight Obesity : An Underrecognized Problem in Individuals of South Asian Descent," Clin. Ther., vol. 41, no. 8, pp. 1638-1642, 2019.

[2] James WPT, R. N, and R. Leach, "The obesity epidemic, metabolic syndrome and future preventive strategies," Eur J Cardiovasc Prev Rehabil, vol. 11, pp. 3-8, 2004.

[3] WHO, "Obesity and overweight," 2019. [Online]. Available: http://who.int/newsroom/fact-sheets/detail/obesity-and-overweight. [Accessed: 06-Nov-2018].

[4] C. Ruano, E. Lucumi, J. Albán, S. Arteaga, and M. Fors, "Obesity and cardio-metabolic risk factors in Ecuadorian university students," Diabetes Metab. Syndr. Clin. Res. Rev., vol. 1871-4021, no. 1003, p. 5, 2018.

[5] R. Leirós-rodríguez, V. Romo-pérez, I. Pérez-ribao, and L. José, "A comparison of three physical activity programs for health and fitness tested with older women: Benefits of aerobic activity, aqua fitness, and strength training," J. Women Aging, vol. 00, no. 00, pp. 1-13, 2018.

[6] Henry C. Lukaski, Body Composition. New York, 2017. 
[7] B. P. Hammond, A. M. Brennan, and R. Ross, "Exercise and Adipose Tissue Redistribution in Overweight and Obese Adults," in Body Composition, H. C. Lukaski, Ed. US: CRC Press, 2017, pp. 109-128.

[8] Omron Healthcare, Instruction Manual Full Body Sensor Body Composition Monitor and Scale. 2008.

[9] O. Pickett-blakely and L. Uwakwe, "O b e s i t y in Wo m e n and Reproductive Health and Disease Management," Gastroenterol. Clin. NA, vol. 45, no. 2, pp. 317-331, 2016.

[10] C. N. Rachmi, M. Li, and L. A. Baur, "Overweight and obesity in Indonesia : prevalence and risk factors $\mathrm{d}$ a literature review," vol. 7, 2017.

[11] R. An, C. Guan, J. Liu, N. Chen, and C. Clarke, "Annals of Epidemiology Original article Trade openness and the obesity epidemic : a cross-national study of 175 countries during 1975 e 2016," Ann. Epidemiol., vol. 37, pp. 31-36, 2019.

[12] K. A. Ahrens et al., "Annals of Epidemiology The effect of physical activity across the menstrual cycle on reproductive function," Ann. Epidemiol., vol. 24, no. 2, pp. 127-134, 2014.

[13] N. Sermondade et al., "Female obesity is negatively associated with live birth rate following IVF : a systematic review and meta-analysis," pp. 1-13, 2019.

[14] A. Talmor and D. Bruce, "Female Obesity and Infertility," Best Pract. Res. Clin. Obstet. Gynaecol., vol. xxx, no. 5, pp. 1-9, 2014.

[15] F. Kiyici, "Metabolic and lipid profile of middle-aged sedentary women doing aerobic exercise plus weightlifting," Procedia - Soc. Behav. Sci., vol. 116, pp. 3935-3939, 2014.

[16] A. E. Hardman and David J. Stensel, Physical Activity And Health. USA And Canada: Routledge, 2003.

[17] S. Pengpid and K. Peltzer, "Diabetes \& Metabolic Syndrome: Clinical Research \& Reviews Underweight and overweight or obesity and associated factors among schoolgoing adolescents in fi ve ASEAN countries , 2015," Diabetes Metab. Syndr. Clin. Res. Rev., vol. 13, no. 6, pp. 3075-3080, 2019.

[18] Jennifer et al., "Effects of Muay Thai training frequency on body composition and physical fitness in healthy untrained women," 2017.

[19] C. Shin, Y. Lee, and M. Belyea, "Physical activity, benefits , and barriers across the aging continuum," Appl. Nurs. Res., vol. 44, no. February, pp. 107-112, 2018.

[20] S. S. Gropper et al., "The impact of physical activity on body weight and fat gains during the first 3 years of college," Int. J. Heal. Promot. Educ., vol. 50, no. 6, pp. 296-310, 2012.

[21] M. Molina, O. López, J. Ma, M. Reyes, R. Burgos, and L. G. De, "Influence ofphysical activity and dietary habits on lipid profile, blood pressure and BMI in subjects with metabolic syndrome," 2011.

[22] F. J. Amaro-gahete, L. Jurado-fasoli, J. R. Ruiz, and M. J. Castillo, Effects of different exercise training programs on body composition: a randomized control trial Different exercise program body composition. .

[23] E. K. Towner et al., "Physical Activity as a Predictor of Changes in Systolic Blood Pressure for African-American Adolescents Seeking Treatment for Obesity," J. Adolesc. Heal., vol. 65, no. 3, pp. 430-432, 2019.

[24] T. O. Bompa and G. G. Haff, Periodization : Theory And Methodology Of Training, Fifth Edit. 2009.

[25] D. A. S. Silva, E. L. Petroski, and A. Pelegrini, "Effects Of Aerobic Exercise On The Body Composition And Lipid Profile," vol. 36, no. 2, pp. 295-309, 2014.

[26] M. Saghebjoo, Z. Nezamdoost, F. Ahmadabadi, and I. Saffari, "Diabetes \& Metabolic Syndrome: Clinical Research \& Reviews The effect of 12 weeks of aerobic training on serum levels high sensitivity C-reactive protein , tumor necrosis factor-alpha , lipid pro fi le and anthropometric characteristics in middle-age women patients with type 2 diabetes," Diabetes Metab. Syndr. Clin. Res. Rev., vol. 12, no. 2, pp. 163-168, 2018. 
[27] M. Rizka, "Pengaruh Latihan Jalan Kaki Terhadap Kebugaran Jasmani Lansia Di Puskesmas Sungai Aur Kabupaten Pasaman Barat,” Stamina, vol. 1, pp. 206-218, 2018.

[28] H. Hürter et al., "Best Practice \& Research Clinical Endocrinology \& Metabolism Prevention of pre-eclampsia after infertility treatment : Preconceptional minimalisation of risk factors," vol. 33, pp. 127-132, 2019.

[29] E. Ubago-guisado, S. Javier, and S. Vila-maldonado, "Effects of Zumba ${ }^{\circledR}$ and Aquagym on Bone Mass in Inactive Middle-Aged Women," Medicina (B. Aires)., vol. 55, no. 23, pp. 1-10, 2019.

[30] S. Barene, P. Krustrup, S. R. Jackman, O. L. Brekke, and A. Holtermann, "Do soccer and Zumba exercise improve fitness and indicators of health among female hospital employees? A 12-week RCT," Scand. J. Med. Sci. Sport., pp. 1-10, 2013.

[31] Y. Barranco-ruiz, M. Guerendiain, and E. Villa-gonz, "Clinical Nutrition Body composition and dairy intake in sedentary employees who participated in a healthy program based on nutrition education and Zumba," Clin. Nutr., no. October, pp. 1-10, 2018.

[32] M. F. Ahmad, M. Amir, and A. Rosli, "Effects of Aerobic Dance on Cardiovascular Level and Body Weight among Women," Int. J. Medical, Heal. Biomed. Bioeng. Pharm. Eng., vol. 9, no. 12, pp. 874-882, 2015.

[33] N. A. for S. and P. Education, Physical Education for Lifelong Fitness, Third. Human Kinetics, 2011.

[34] A. J. Alford, M. White, L. Lockwood, A. Hallahan, and P. S. W. Davies, "Body composition, dietary intake and physical activity of young survivors of childhood cancer," Clin. Nutr., no. March, pp. 1-6, 2018.

[35] S. Haldar, S. C. Chia, and C. J. Henry, Body Composition in Asians and Caucasians: Comparative Analyses and Influences on Cardiometabolic Outcomes, 1st ed., vol. 75. Elsevier Inc., 2015.

[36] M. Skalska, "Body composition, physical fitness, physical activity and nutrition in Polish and Spanish Composition corporelle , condition physique , activité physique," 2019.

[37] S. E. Crouter, C. Salas, and J. Wiecha, "Effects of an afterschool community center physical activity program on fitness and body composition in obese youth," J. Sports Sci., vol. 0414, no. July, 2016. 